\title{
Las abreviaturas en cuatro ediciones tempranas de la Celestina: Toledo 1500, Burgos 1499-1502 (?), Zaragoza 1507 y Valencia 1514. Catalogación, cuantificación y consecuencias editoriales ${ }^{1}$
}

\author{
Antonio Sánchez Sánchez-Serrano \\ Ex profesor de la Universidad Complutense
}

\begin{abstract}
Preámbulo
Las razones que nos han movido a elegir las ediciones que indica el título son fundamentalmente dos. Una es de orden práctico: de las cuatro existen ediciones facsimilares fiables para nuestro objetivo y por lo tanto de fácil consulta a quien quiera verificar, utilizar o prolongar nuestros datos, o complementar nuestras propias observaciones. La otra razón es de carácter metodológico: la de Toledo y la de Burgos son representativas de la versión en 16 autos titulada Comedia de Calisto y Melibea y objetos de numerosos estudios actuales; la de Zaragoza y la de Valencia son prototipos peculiares de la versión en 21 autos, la primera por ser la edición más antigua conocida de la Tragicomedia de Calisto y Melibea (salvo la traducción al italiano de Alfonso Ordóñez editada en 1506 en Roma) y la única en no incluir los "argumentos» de cada uno de los autos, y la segunda por haber sido revisada, muy posiblemente, por el humanista y catedrático de la Universidad de Valencia Alonso de Proaza².

Ninguna de las dos Tragicomedias presenta problema alguno de datación, no así la Comedia de Burgos, cuya prioridad o posterioridad cronológica respecto a la de Toledo ha devenido en un asunto candente que no conviene obviar porque roza nuestras conclusiones.

1.- Este trabajo fue presentado en las XIII Jornadas de Trabajo de la Asociación Española de Bibliografía el 20 de diciembre de 2013 en la Biblioteca Nacional de España.

2.- Así lo afirman o sugieren, entre otros, McPheeters (1961: 189-193), Marciales (1985: I: 231-232), Norton (1997: 214), Salvador Miguel (1999: 15), Canet (1999: 35), Serés (2000: lxxv), Infantes (2007: 14-15 y 85-86), Patrizia Botta (1999: 24-25) y Antonio Sánchez y Remedios Prieto (2009: 165-168 y 2011: 90-91).
\end{abstract}


Es sabido que el único ejemplar que se conserva de la edición de Burgos está incompleto (carece de portada y de paratextos) y que ofrece pruebas de su manipulación en el siglo XIx. Según la marca del impresor estampada en el recto de la última hoja, la edición salió del taller de Fadrique de Basilea en 1499, fecha que fue aceptada mayoritariamente ${ }^{3}$ durante el siglo $\mathrm{xx}$, aunque con reservas, y defendida concienzudamente por el hispanista Ottavio Di Camillo (2005a y 2005b) en el siglo actual. Sin embargo, como el taco de este xilograbado fue utilizado en libros salidos de la imprenta de Fadrique de Basilea hasta 1502 y la hoja no es original sino un facsímil moderno, expertos en Bibliografía como Julián Martín Abad (2001), Mercedes Fernández Valladares (2005: I: 352-368), Víctor Infantes (2010: 28-46), Jaime Moll (2011: 263-268) o José Luis Canet (2011: 15, 101 y 110) la han fechado, aunque con matices, entre 1500 y 1502. Los argumentos para defender o anular la anterioridad de Burgos sobre la de Toledo no se basan solo en la marca del impresor en esa hoja apócrifa, también se esgrimen otros que ahora no vienen al caso y que el lector interesado podrá valorar por sí mismo consultando los estudios de los críticos citados.

La de Burgos es una edición de lujo, muy cuidada y con 17 ilustraciones historiadas cuya excelencia ha puesto de relieve Joseph T. Snow (1990: 255-277; 2005: 111-129) ${ }^{4}$. Por el contrario, la de Toledo carece de ilustraciones y adolece de descuidos.

No parece que haya duda de que la edición de Toledo fue estampada en 1500 en el taller tipográfico de Pedro Hagenbach. El único ejemplar que se conserva está completo: lleva todos los paratextos propios de la versión en 16 autos: al principio, la Carta de "El autor a un su amigo", los versos acrósticos, el «Síguese» o Incipit y el Argumento general; y al final, los versos del "corrector de la impresión» Alonso de Proaza. Es una edición con numerosos fallos de composición en la mayoría de los pliegos, como han señalado Francisco Rico (2000: 230-233), Fidel Sebastián (2003:121-122), Jaime Moll (2011:269-272), y José Luis Canet (2011: 114-129). A los fallos resaltados por estos críticos, nosotros añadiremos las irregularidades en el uso de las abreviaturas en los nombres de los personajes.

Las cuatro editan la obra como anónima, sin el nombre de Fernando de Rojas en la portada ${ }^{5}$ y así las presentamos nosotros en la Bibliografía que

3.- A contracorriente de la mayoría destaca Montañés Fontenla (1973), quien apoyándose en dictámenes de bibliógrafos como Vindel y Palau Claveras, postula la anterioridad de la edición de Toledo sobre la de Burgos.

4.- Fernando Cantalapiedra (2011: 36-50) estudia detenidamente la relación de estos xilograbados con los de las ediciones terencianas de Grüninger, Estrasburgo 1496 y 1499.

5.- Respecto a la consideración del carácter anónimo de la obra, el desconocimiento en que tuvieron a Fernando de Rojas sus contemporáneos como autor/creador de la Celestina y la ausencia total de su nombre en las portadas hasta bien entrado el siglo XIX, véanse Antonio Sánchez Sánchez-Serrano (1985 y 2001), Remedios Prieto de la Iglesia (2000 y 2001), Anto- 
cierra este estudio realizado desde la perspectiva de la materialidad del libro antiguo y los primeros tiempos de la imprenta.

\section{Ajuste de líneas y planas y ahorro de papel}

Un examen superficial de una página elegida al azar (exceptuando las de los paratextos, las que contienen grabados o aquellas otras en las que se materializa el paso de un auto a otro) de cualquiera de las cuatro ediciones objeto de nuestro estudio, muestra una presentación del texto bien distinta a la de las ediciones modernas, compacta, densa, a renglón seguido, sin punto y aparte entre un parlamento y otro y por tanto sin espacios en blanco que indiquen el cambio de interlocutores. Esta densidad permite deducir la tendencia a acoplar el texto de la obra a un número mínimo de páginas con el consiguiente ahorro de papel, que, en palabras de Pedraza Gracia (2008: 237), era «el gasto principal de la producción del libro"; lo cual no invalida la influencia de la tradición del libro manuscrito (Mckerrow 1998: 329) ni la de los usos de escritura y hábitos de lectura, especialmente en lo concerniente al uso de abreviaturas (A. B. Sánchez Prieto, 2001: 167).

El condicionamiento que suponía el ajuste de líneas y planas y los recursos utilizados por los cajistas ${ }^{6}$ para su logro son fáciles de comprobar en cualquiera de las cuatro ediciones.

Tomemos como ejemplo la página de la edición de Toledo $\left[\mathrm{a}_{\mathrm{iiij}}\right]^{\mathrm{T}}$ (LÁMINA 1). Observemos que en el final de las líneas 3, 15, 16, 18 y 31 hay dos pequeños trazos paralelos oblicuos (//) que, aparentemente, tienen una función análoga a la del guión que actualmente nosotros empleamos para atestiguar que el final de un renglón y el principio del siguiente

nio Sánchez Sánchez-Serrano y Remedios Prieto de la Iglesia (1991: 13-26 y 2011: 163-168) y Joseph T. Snow (2005-2006). Es de notar que en relación con la autoría de la obra, una parte de la actual crítica celestinesca, frente a la postura tradicional, tiende a disminuir el papel de Rojas, tales como, además de los estudiosos citados, Fernando Cantalapiedra (2000, 2001 y 2011, fundamentalmente), García Valdecasas (2000), Ottavio Di Camillo (2005b: 240-241), Govert Westerveld (2005-2009), José Antonio Bernaldo de Quirós (2010 y 2012 especialmente), Devid Paolini (2011) y José Luis Canet Vallés (2011). Se podría decir que en los planteamientos de todos estos críticos, Rojas es «el autor» (no creador) en el sentido de «acabar», rescribir, corregir, preparar para la imprenta una obra preexistente sacándola a luz, si bien la intervención que cada uno le asigna a Rojas es de mayor o menor envergadura, incluso mínima según los postulados de Di Camillo, Snow y Canet.

6.- Para una amplia panorámica concreta y secuenciada del trabajo realizado en los talleres tipográficos en la época de la imprenta manual es muy clarificador el detenido artículo de Sonia Garza Merino (2000: 65-95). También Manuel José Pedraza (2003: 104-118) se centra muy detalladamente en el proceso de imprimir y en la labor de los cajistas, como se les denomina en la actualidad, o componedores, como se les llamaba antiguamente.

7.- Citamos por la signatura del impreso: letra del cuaderno y número de la plana, recto (r) y vuelto (v) seguido del número de la línea cuando resulte oportuno. 
pertenecen a una sola palabra: "ga//lardon", "ter//nia", "galar//don", "oy//do", «infortu//nio». Ahora bien, si nos fijamos en el final de la línea 10, veremos que "pura mente» carece de dicho signo de unión, y lo mismo observamos en la línea 17 con "ore jas", en la 20 con "atreui miento», en la 21 con «in genio», en la 26 con "for tuna» y en la 27 con "sempro nio». Esto es, que utilizaban o no utilizaban los dos trazos paralelos y oblicuos en función de la necesidad de ajustar las líneas, aunque, eso sí, el cajista los introducía únicamente en el caso de fraccionamiento de palabras. Y esto era norma general en las imprentas de la época y asimismo en las posteriores.

También era habitual $-\mathrm{y}$ nuestras cuatro ediciones así lo testimonian- que los cajistas, ante la necesidad de justificar las líneas y cuadrar el texto dentro de la caja de la plana, se tomaran otras libertades, la mayoría destinadas a embeber el texto ${ }^{8}$, y que podríamos definir en forma expresiva diciendo que lo ortográfico quedaba supeditado a lo gráfico.

Tales licencias tipográficas son:

- Reducción de los espacios en blanco (empleando cuadratines muy estrechos) entre palabras (como en la misma página de la edición de Toledo, línea 20: «tu loco»), incluso uniéndolas totalmente para ahorrar espacio y justificar la línea, como al final de las líneas 6 ("enesta»), 8 ("enla») y 30 ("enel»).

- Uso de mayúsculas o de minúsculas en los nombres propios (LÁMINA 2) -así en la plana $\left[\mathrm{a}_{\mathrm{i}}{ }^{\mathrm{r}}\right]$ de la edición burgalesa, donde aparecen "Calisto», "Melibea», "Sempronio» y "Parmeno», y también "calisto», "sempronio», "elicia», "celestina», "crito» y "parmeno»— ya que por término medio una mayúscula ocupa el doble de espacio que la correspondiente minúscula.

- Supresión de puntos, fenómeno que tendremos ocasión de comprobar en el presente estudio.

- Alteraciones voluntarias de la ortografía, como en casos que asimismo tendremos ocasión de mostrar.

- Por último, no podemos descartar en absoluto que también obedezca a esta necesidad, no solo a descuido, la omisión de alguna preposición o artículo.

8.- También el cajista empleaba artificios en el caso de que le faltara texto para ajustar líneas y planas, como por ejemplo, ampliar los espacios en blanco o introducir palabras sin cambiar el sentido del texto, fenómenos estos atribuibles a la mala cuenta del original y que se pueden observar en la edición de Toledo, tal como han señalado Francisco Rico (2000: 230-239) y José Luis Canet (2011: 114 y ss.). En cuanto a la reducción de líneas en esta misma edición, véase, además de Canet, Fidel Sebastián Mediavilla (2003: 121-122) y Jaime Moll (2011: 269-272), que estudian la reducción de líneas en la caja de las planas f iij r, f iij v, f iiij r, f iiij v, f v r, f v v, f vj r, f vj v, que pasan de las 32 líneas habituales a 30.A esto hay que añadir otro caso que ha pasado desapercibido (al menos nosotros no tenemos noticia): la plana $b$ vj r tiene 31 líneas. 
Pero el gran recurso tanto para la justificación de las líneas y de las planas, así como para materializar la tendencia al ahorro de papel, es el uso de abreviaturas.

A lo largo de varios meses hemos ido anotando, página a página de cada una de las cuatro ediciones, el número de letras ahorradas con las abreviaturas, y los resultados son los siguientes:

$\begin{array}{ll}\text { Toledo: } & 12.478 \\ \text { Burgos: } & 13.512 \\ \text { Zaragoza: } & 18.166 \\ \text { Valencia: } & 17.573\end{array}$

Si bien en este otro caso nuestros cálculos no pueden ser tan exactos, como la media de letras por página en cada una de dichas ediciones es:

$\begin{array}{ll}\text { Toledo: } & 1440 \\ \text { Burgos: } & 1290 \\ \text { Zaragoza: } & 1938 \\ \text { Valencia: } & 2390\end{array}$

bastaría con dividir las cifras de arriba por las de abajo para deducir que el número de páginas ahorradas por las abreviaturas en cada edición sería respectivamente:

$\begin{array}{lc}\text { Toledo: } & 8,6 \\ \text { Burgos: } & 10,4 \\ \text { Zaragoza: } & 9,3 \\ \text { Valencia: } & 7,35\end{array}$

y como en cada pliego, para un libro de formato en cuarto como son los que nos ocupan, se estampaban ocho planas, quiere decirse que el ahorro, solo en abreviaturas (sin tener en cuenta los espacios ahorrados con las licencias tipográficas), supone algo más de un pliego en las tres primeras ediciones y algo menos en la de Valencia, debiendo aclarar que nuestros cálculos se quedan algo cortos pues no hemos tenido en cuenta el espacio ahorrado por las abreviaturas de los paratextos en prosa.

En cuanto a los versos iniciales y finales, en los que un ahorro de letras no implicaría un ahorro de espacio ya que en este caso no hay ajuste de líneas, las abreviaturas son prácticamente inexistentes en el texto de las estrofas (no en el de las rúbricas en prosa). No las hay ni en la edición de Toledo ni en la de Valencia (el ejemplar de Burgos carece de versos); solo se constatan tres casos de abreviaturas en los versos de la edición de Zaragoza: $q<$ ue $>\left(a_{\text {iij }}{ }^{\text {r: }} 6\right)$ y porq $<$ ue $>\left(a_{\text {iij }}\right.$ : 17$)$, con la línea de abreviación general sobre la $q$, yama $<\mathrm{n}>$ tes $\left(\mathrm{i}_{\text {viii }}\right.$ r: 32 ), con la línea de abreviación sobrescrita en la $a^{9}$. Cabe interpretar esta excepcional falta de abreviaturas

9.- Ante la dificultad de reproducir actualmente los signos tipográficos de la imprenta manual, optamos por describir sus formas e introducir entre corchetes angulares las letras suprimidas. 
en los textos versificados como un comprobante de que la finalidad del ahorro de papel era inherente a su uso.

Parece lógico que tal ahorro de papel, que también conlleva el de las prensas, tinta, tiempo y trabajo de los cajistas, batidores, tiradores y demás operarios del taller tipográfico, debía formar parte de los cálculos previos que el maestro del taller haría, a la vista del original (manuscrito o impreso), para determinar el número de pliegos y planas de cada edición y por consiguiente su coste y tiempo de la estampación ${ }^{10}$. El ahorro pues no era despreciable y más si se piensa en una media entre 500 y 1500 ejemplares por tirada ${ }^{11}$ cuyo coste era tan elevado que se necesitaba invertir un gran capital ${ }^{12}$.

Centrándonos ya en el estudio de abreviaturas, empezaremos por hacer una distinción fundamental: por una parte, el de las acotaciones nominales que designan a los interlocutores cuando toman la palabra, escritos de forma abreviada por suspensión salvo excepciones, y, por otra, los nombres de los personajes que estos citan o interpelan, abreviados solo excepcionalmente. Finalmente, presentaremos una muestra de los distintos tipos de abreviaturas por contracción empleados en el texto de los diálogos de las cuatro ediciones.

\section{Las abreviaturas en las acotaciones nominales y sus excepciones}

La norma general para estas acotaciones que designan a los personajes que van a hablar es la abreviación por suspensión, tomando las primeras letras de cada nombre - dos, tres, cuatro, cinco e incluso seis, según convenga para el ajuste de las líneas-y colocando un punto a continuación de ellas:

10.- Con respecto a la responsabilidad del maestro del taller (empresario además de impresor) en el proceso de producción, control del gasto, abastecimiento del papel, cálculo de pliegos, etc., véase Pedraza Gracia (2008: 200-293).

11.- En relación con el número de ejemplares por tirada, pueden consultarse: McKerrow (1998: 156-158), Pedraza Gracia (2008: 285-286), Canet (2009: 63-66) o Moll (2011: 124), entre otros.

12.- Aunque hasta la fecha no se haya encontrado contrato alguno de edición de ninguna de las estampaciones de la Celestina, sí existen de otros libros que pueden orientarnos sobre su costo. Así, el profesor Canet (2007: 34 y 2011: 20) hipotetiza con fundamento que la edición de la Comedia de Calisto y Melibea realizada en Toledo en la imprenta de Hagenbach, con una tirada de 1000 ejemplares de 80 hojas, pudo haber costado aproximadamente entre 160 y 180 ducados de oro; o unas 60 libras valencianas si se piensa en una edición de 500 ejemplares, cuyo valor podremos juzgar fácilmente si tenemos en cuenta que un catedrático de la Universidad de Valencia cobraba al año entre 15 y 35 libras valencianas, según la cátedra. Muy interesante para hacernos idea del precio del papel es este dato concreto: "Un libro en $4^{\circ}$ con 146 hs. de 22 líneas, caso del Ordinarium de Mallorca, impreso en Valencia por Jofré, costó al librero Gabriel Fábregues, mallorquín, entre setenta y dos y noventa y nueve libras valencianas, según el precio del papel que haya usado, por los 500 ejemplares de la edición». (Canet 2011: 20). 


$$
\begin{aligned}
& \text { Me., Meli., Ca., Cali., Sem., Semp., Sempro., Ce., Cele., } \\
& \text { Celest., Eli., Par., Parme., Lu., Lucre., Ali., Are., Areu., Ple., } \\
& \text { Plebe., Tri., Trist., So. }
\end{aligned}
$$

Pero esta norma general no carece de excepciones, muy abundantes en la edición de Toledo y mucho más limitadas en la de Burgos. Las de Zaragoza y Valencia no merecen la pena que las analicemos por la razón que se expondrá en su momento. (Puede verse una panorámica-resumen de las acotaciones nominales en la Lámina 3).

La edición de Toledo incluye 1132 acotaciones nominales. La mayoría, 909, siguen la norma general y por lo tanto no vamos a detenernos en ellas. Lo interesante son sus numerosísimas excepciones, consistentes en utilizar la suspensión combinada con la contracción de la vocal e para Sempronio $(S e<m>$.) y en escribir el nombre completo de los personajes. Así pues, las 1132 acotaciones nominales de la edición de Toledo pueden quedar distribuidas en tres grandes grupos:

$$
\begin{aligned}
& \text { A.- Abreviaturas por suspensión............... } 909 \\
& \text { B.- Contracción }+ \text { suspensión }(S e<m>\text {.)... } 94 \\
& \text { C.- Nombre completo ................................ } 129 \\
& \text { TOTAL DE ACOTACIONES..................1132 }
\end{aligned}
$$

Teniendo en cuenta que el grupo B, reducido a la expresión «Se $<\mathrm{m}>$.» puede asimilarse al grupo A, lo verdaderamente importante para extraer consecuencias es ese núcleo $\mathrm{C}$, en el que encontramos las siguientes variedades:

$\mathrm{C}_{1}$ - Nombre completo con mayúscula inicial y seguido de punto

$$
(.)=53 \text { veces }^{13} \text {. }
$$

$\mathrm{C}_{2}$ - Nombre completo con mayúscula inicial y seguido de dos puntos $(:)=10$ veces $^{14}$.

$\mathrm{C}_{3}$ - Nombre completo con mayúscula inicial seguido de vírgula $(/)=1 \mathrm{vez}^{15}$.

$\mathrm{C}_{4}-$ Nombre completo con mayúscula inicial y sin puntuación final $=64$ veces $^{16}$.

13.- Toledo. Nombre completo con mayúscula inicial y seguido de punto: Calisto. (a vij r:32, c iij r:25), Sempronio. (f vij r:12), Celestina. (b vj r:4, b vj r:10, b vjr:19, b vj r:24, b viij v:19, f ij v:29, f iij r:1, f iij r:29, f iij v:13,f iij v:16, f iij v:22, f iij v:31, f iiij r:9, f iiij r:20, f v v:26, f vj r:14, c vj v:23 [errata]), Elicia. (b j r:12, c vj v:21, f v v:11 [errata],f vj r:19 [errata], f vj r:15 [errata]), Crito. (b j r:15),Parmeno. (b vj r:14, b vj r:23, b viij v:13, c iij r:6, c iij r:26, c iiij r:9, f iiij v:27, f vj v:7, f vj v:10, f vj v:13, f vj v:14), Areusa. (f ij v:6, f ij v: 12,f ij v:14, fij v:19, fij v:30, f iij v:10, fiij v:14, f iij v:28, f iiij r:8, f iiij r:13, f iiij v:23, f v r:9, f vj v:3, f vj v:11, f vj v:13, f vj v:22).

14.- Toledo. Nombre completo con mayúscula inicial seguido de dos puntos: Sempronio: (f vij r:25,f vij r:30), Celestina: (f ij v:3, fiiij r:23), Parmeno: (f v v:8, f vij r:26, f viij v:6), Areusa: (f

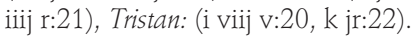

15.- Toledo. Nombre completo seguido de vírgula: Celestina / (f v v:22).

16.- Toledo. Nombre completo con mayúscula inicial y sin puntuación final: Melibea (d iiij v:16), Calisto (c iiij r:5, c iiij r:7, e ij v:24, i vj r:27), Sempronio (c iiij v:1-2, c v r:32, f viij v:6, f viij 
$\mathrm{C}_{5}$ - Nombre completo con minúscula inicial y seguido de punto $=1 \mathrm{vez}^{17}$

TOTAL DE ACOTACIONES IRREGULARES $=129$

En algunas acotaciones existen erratas: En el grupo A se emplean 2 veces «Ce.» $\left(e_{i i i j}^{r: 4}, g_{j}{ }^{v: 4}\right)$ y una "Cae.», con ae ligadas en un único cuerpo $\left(\mathrm{d}_{\text {viii }}^{\mathrm{v}: 12}\right)$, para Calisto; 2 veces "Celi.» $\left(b_{i}{ }^{\mathrm{r}: 12}, \mathrm{c}_{\mathrm{vi}}^{\mathrm{v}: 26}\right)$ para Celestina, y una vez «Sem:» $\left(\mathrm{a}_{\mathrm{iiij}}\right.$ v:30) para Sempronio. En el $\mathrm{C}_{1}, 3$ veces «Elisa.» $\left(\mathrm{f}_{\mathrm{v}}^{\mathrm{v}: 11}, \mathrm{f}_{\mathrm{vi}}\right.$ $\mathrm{r}: 19, \mathrm{f}_{\mathrm{vi}}^{\mathrm{r}: 15}$ ) por Elicia, y una «Celicia.» $\left(\mathrm{c}_{\mathrm{vj}}^{\mathrm{v}: 23}\right.$ ) por Celestina. Y en el $\mathrm{C}_{4}, 3$ veces «Elisa» $\left(\mathrm{f}_{\mathrm{v}}^{\mathrm{v}: 12-13}, \mathrm{f}_{\mathrm{v}}{ }^{\mathrm{v}: 14}, \mathrm{f}_{\mathrm{v}}{ }^{\mathrm{v}: 28}\right)$ por Elicia, $\mathrm{y}$ una vez «Parmenio» $\left(\mathrm{f}_{\mathrm{vii}}{ }_{\mathrm{v}: 23}\right)$ por Parmeno.

Además en una ocasión no existe una réplica de Areúsa con su correspondiente acotación $\left(f_{v j}^{v: 10}\right)^{18}$, que sí está en las demás ediciones, y, en otra ocasión, se ha omitido la acotación nominal de Sosia en una contestación de este personaje a Calisto, aunque se incluyan las palabras de su réplica $\left(i_{\mathrm{vi}}{ }^{\mathrm{v}: 31}\right)^{19}$.

Si tenemos en cuenta que la obra estaba destinada a la lectura en voz alta ante un público oyente, según lo atestigua Alonso de Proaza en sus versos:

\section{DiZe EL MODO QUe SE HA DE TENER LEYENDO ESTA COMEDIA}

Si [a]mas y quieres a mucha atencion leyendo a Calisto mouer los oyentes. cumple que sepas hablar entre dientes: a vezes con gozo: esperança: y passion a vezes con ayrado con gran turbación: finge leyendo mill artes: $y$ modos: pregunta: $y$ responde por boca de todos: llorando y riendo en tiempo y sazon. ${ }^{20}$

$$
\text { (Toledo, } \mathrm{k}_{\mathrm{vij}}^{\mathrm{v}: 29-32}-\mathrm{k}_{\mathrm{viij}}^{\mathrm{r}: 1-6} \text { ) }
$$

es lógico suponer que el lector que quisiera leer del modo que aconseja Proaza, entonando y dando sentido a lo que leía, experimentaría dudas y

v:17, f viij v:22, f viij v:25), Celestina (b vj r:13, c iiij v:1, c v r:12, c v r:21, d iiij v:14, d v r:2-3, f ij v:9, f ij v:13, f ij v:20, f iij r:5, fiij v:9, f iiij v:25, fiiij v:29, fv r:16-17, fv r:25, f v r:29, fv v:9, f v v:12, f v v:13, f v v:30, h j v:16-17, h vj r:5-6), Elicia (c vj v:26, f v v:12-13 [errata], f v v:14 [errata],f v v:28 [errata]), Parmeno (b vj r:29, c iij r:11-12, c iiij r:6, f v r:10-11, f v r:24, f vj v:24, f vij r:18, f viij v:1, f viij v:16-17, f viij v:21, f viij v:27-28, f viij v:23 [errata]), Areusa (f ij v:2, f ij v:2, f iij r:4, f iij v:18, f iiij v:23 ,f v r:15 ,f v r:28 ,f v v:7-8), Tristan ( i vj r:22, i vjr:25, i vj r:27, i vj r:29, i vj v:10, i viij r:13-14), Sosia (i vj v:12-13).

17.- Toledo. Nombre completo con minúscula inicial seguido de punto: parmeno. (b vj r:6).

18.- Se ha omitido: [Areusa.- ¿Tarde?] (Auto viII).

19.- [So.] Señor la causa de su muerte publicaua el verdugo. (Auto XIII).

20.- La ortografía, incluyendo la puntuación, se corresponde con la original de la edición de Toledo, que, como las otras tres ediciones, desconoce la coma (,), en cuyo lugar usa dos puntos (:) o un punto (.), dependiendo del tipo de pausa. Véase la nota siguiente. 
quizá sufriría alguna sensación embarazosa, sobre todo en casos concretos como el que analizaremos más adelante. Esto originaría comentarios desfavorables y la prueba de ello es que, como vamos a comprobar, en las demás ediciones se refleja una preocupación constante por subsanar estas irregularidades con soluciones cada vez mejores.

En la edición de Burgos, la distribución de las acotaciones es como sigue:
A.- Abreviaturas por suspensión: 1046
B.- Contracción + suspensión $(S e<m>$. .........83
C. - Nombre completo
TOTAL DE ACOTACIONES .....................1134

Lo primero que se observa es que hay dos acotaciones más que corresponden a la de Areúsa y a la de Sosia omitidas en Toledo.

En el grupo A hay dos acotaciones sin punto: $S_{e}<m>\left(\mathrm{a}_{\mathrm{iiij}} \mathrm{r}: 17\right)$ y $\mathrm{Ca}\left(\mathrm{k}_{\mathrm{iiij}}\right.$ $\mathrm{v}: 7)$, explicables por necesidades de justificación de las líneas.

El grupo B, como en el caso anterior, puede asimilarse al A, ya que lo verdaderamente importante es la supresión de las letras finales.

El grupo C queda reducido únicamente a cinco casos: 2 veces Calisto. (a ${ }^{\mathrm{r}: 25}, \mathrm{a}_{\mathrm{v}}^{\mathrm{r}: 15}$ ) y una respectivamente Elicia. $\left(\mathrm{a}_{\mathrm{vij}}{ }_{\mathrm{rij}} 20\right.$ ), Crito. $\left(\mathrm{a}_{\mathrm{vij}}^{\mathrm{ri}}\right.$ ) y Parmeno. $\left(\mathrm{b}_{\mathrm{vj}}{ }_{\mathrm{v}}^{\mathrm{r}: 28}\right)$, y no ofrecen posibilidades de dudas al lector ya que todas llevan su correspondiente punto.

Tampoco se registran erratas en estas acotaciones nominales, aunque sí hay que tener en cuenta una circunstancia especial respecto a la abreviatura de Sempronio: en seis ocasiones la acotación abreviada es Sen. [a ${ }_{\text {vij: }}^{v: 12}, e_{\text {iij: }}^{r: 3}, g_{v i j}^{r: 2}, i_{v j}^{r: 17}, k_{v}^{r: 7}, k_{v}^{r: 9}$ ] en lugar de $S e m$. o $S e<m>$., cuyo uso es comprensible por la necesidad de ajustar las líneas. Nos encontramos pues ante una prueba de la modificación voluntaria de la ortografía por parte del cajista para justificar líneas en las que era difícil hacer uso de otro artificio, según puede percibirse en la plana [a ${ }_{\mathrm{vij}}^{\mathrm{v}: 12}$ ] (LÁMINA n 4), donde el cajista solo podía recurrir al cambio de la $m$ por la $n$ para ajustar la línea pues los dos puntos (..) con que termina la réplica anterior de Sempronio son inamovibles, los dos son preceptivos: uno cierra sus palabras y el otro equivale a un signo de interrogación ${ }^{21}$.

Finalmente, las ediciones de la Tragicomedia de Zaragoza y Valencia encuentran una solución perfecta para evitar confusionismos: encerrar entre paréntesis las acotaciones nominales, con lo cual resultaba imposible cualquier duda del lector respecto a la identidad del personaje que habla. Además, estas dos ediciones suprimen las acotaciones con el nom-

21.- La edición de Burgos carece de signos de interrogación, que quedan suplidos por el punto (.), según ha estudiado con todo detalle Fidel Sebastián Mediavilla (2003: 124-126). En cuestión de puntuación, la edición de Burgos sigue estrictamente las normas de Nebrija en Introductiones in latinam grammaticam, impresa en 1502, en donde "apuesta por tan solo dos signos de puntuación, el punto y los dos puntos. [...] En lugar del interrogante, se sirve del punto seguido [...], no hay comas ni vírgulas oblicuas, ni, por supuesto, punto y coma.»(Fidel Sebastián 2003: 118). 
bre completo, con una única excepción en la de Zaragoza en la primera intervención de Alisa $\left(\mathrm{c}_{\mathrm{iiij}}\right.$ v:14)$)$. No hay erratas, salvo dos en la de Valencia: «(Ce.)» para Calisto ( $\left.\mathrm{d}_{\mathrm{r}}^{\mathrm{r}: 34}\right) \mathrm{y}$ «(Ca.)» $\left(\mathrm{f}_{\mathrm{iij}}^{\mathrm{v}: 34}\right.$ ) para Celestina. Unas acotaciones llevan punto (.) y otras no, dependiendo de las necesidades de justificación de las líneas.

\section{Las abreviaturas excepcionales en los nombres de los personajes integrados en los diálogos}

Respecto a los nombres de los personajes integrados en el texto de los diálogos — 466 en Toledo y 467 en Burgos ${ }^{22}$ ya que, en una pregunta de Sempronio del Auto XI, la edición de Burgos inserta el nombre de Pármeno $\left(i_{v j}{ }^{r: 26}\right)$ mientras que en la de Toledo no aparece $\left(h_{v}{ }_{v}^{v: 17-18}\right)^{23}$ - la norma general es la utilización del nombre completo, si bien hay excepciones. (Puede verse una panorámica-resumen en la lámina $\mathrm{n}^{\circ}$ 5).

Una excepción a esta norma general se produce en el nombre de Sempronio, ya que en las cuatro ediciones se abrevia en ocasiones con la forma $S e<m>$ pronio, sustituyendo la grafía aquí utilizada $<$ m $>$ por la línea general de abreviación sobrescrita en la e. Esta circunstancia se produce 58 veces en la edición de Toledo ${ }^{24}, 4$ en la de Burgos ${ }^{25}, 24$ en Zaragoza ${ }^{26}$ y 20 en Valencia ${ }^{27}$; sin embargo, este tipo de abreviatura por contracción de vocal precediendo a una consonante nasal no es más que un recurso común usado en múltiples ocasiones por los cajistas para justificar la línea ahorrando un espacio dentro del texto de los diálogos. Caso semejante es el del nombre de Trista $<\mathrm{n}>$ en las ediciones de Toledo ( $\mathrm{i}_{\text {viij }}^{\text {r:13 }}$ ), Zaragoza

22.- En este cómputo no tenemos en cuenta a los que no son actantes, caso de Cremes, Alberto, Claudiana o Eliso.

23.- Edición de Burgos: Sem. de que te ries por tu vida parmeno. Par. de la priessa que la vieja tiene por yr se. Edición de Toledo: Sem. de que te ries por tu vida? Par. de la priessa que la vieja tiene poryrse. (Auto XI)

24.-He aquí las localizaciones de $S e<m>$ pronio en la edición de Toledo: a v v:25, b ij r:18, b iiij r:17, b iiijr:24-25, b iiij v:5, b iiij v:14, b iiij v:32, b v r:11, b vij v:7-8, b viij r:8, c j r:6, c j r28-29, c j v:8, c ij r:21, c ij v:27, c ij v:31, c vj v:21-22, c vij r:7, c vij r:13, d vij v:9, d vij v:25, d viij r:7, d viij r:18, d viij r.27, d viij v:25, d viij v:30, e j r:23, e j v:26, e ij v:13, e ij v:29, e iij v:26, e iij v:28, e vj v:4, e vij v:7, e vij v:15, e vij v:19, e vij r:24, e viij r:19, e viij r:24, fvij r:18, f vij v:6-7, g j r:9,g j v:5, g ij v:31, h vj v:1-2, h vj v:5, h vj v:15, i j r:17, i iij r:18, i iij v:17, i iiij r:10, i iiij r:18, i iiij r:20, i vj r:21-22, i vj v:11, i vj v:11, i vj v:20, i vj r:21-22.

25.- Localizaciones de Se<m>pronio en la edición de Burgos: a v v:20, a vij r:12, b viij v:34, g jv:3.

26.- Localizaciones en la edición de Zaragoza: a v v:13, a v v:13, a vj v:22, a vij v:32, a viij v:22, a viij v:32, b iij r:19,b iij r:30, c iij r:3, c iij v:26,d j v:26, d ij v:17, d iij r:34, d viij r:37, e iij r:3, e vij v:3, g j v:10, g j v:24, g iij r:35, g v r:32, g v v:16, g vj v:2, g vij v:10, h iiij v:19.

27.- Localizaciones en la edición de Valencia: b vij r:15, c j r:41, c ij r:7, c vij v:40, c viij v:28, d j r:26, d v v:26, d vj r:11, e ij v:8, e ij v:25, fvv:24, fvv:36, fvj r:7, g iij v:1, g iij v:2, g iij v:16, $\mathrm{g}$ viij r:27, g viij r:34, h iij r:35, h iiij r:25. 
$\left(h_{i i j} v: 8, i_{i i j}^{r: 2}, i_{i i j}^{v: 6}, i_{i i i j}^{v}: 36\right)$ y Valencia $\left(g_{v}^{r: 27}, h_{v j}^{v: 12}, h_{v i i j}^{v: 15}\right)$. Otras abreviaturas por contracción se comentarán posteriormente.

La excepción verdaderamente importante por las conclusiones que nos permite extraer, es que la edición de Toledo utiliza también aquí las abreviaturas por suspensión:

$$
\begin{aligned}
& \text { Me. (4), Meli. (1), Ca. (1), Cali. (1), Se<m>. (4), Sem. (2), } \\
& \text { Ce. (1), Eli. (1), Par. (3+1 } \left.{ }^{28}\right) \text {, Lu. (1), Lucre. (1) }{ }^{29} \text {. }
\end{aligned}
$$

las cuales, salvo Lucre., son utilizadas igualmente para las acotaciones nominales, lo que añadiría más probabilidades de fallos y situaciones embarazosas para el lector en alta voz. Muy elocuente al respecto es un fragmento de un parlamento de Celestina en el Auto vi que, a causa de esa utilización de nombres completos en las acotaciones nominales (129 veces, como ya vimos) y de abreviaturas por suspensión en los nombres mencionados en los diálogos (21 veces), junto con el uso bastante indiscriminado de letras mayúsculas y signos de puntuación como se ha visto en el apartado anterior, resulta realmente incomprensible y haría pasar algún mal rato al lector en alta voz ${ }^{30}$ :

Ce. [...] Y como le fuesse necessario absentarse dexo en su lugar a Melibea para Calisto o gozo sin Par. o singular

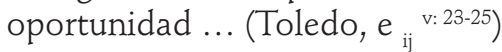

y realmente tampoco lo comprenderíamos nosotros si no conociéramos la trama de la Celestina o no tuviéramos otras ediciones que nos lo aclararan.

La edición de Burgos evita prácticamente las posibilidades de error. Se ciñe en mayor medida a las normas generales, puesto que, como dijimos, solo utiliza en cinco ocasiones el nombre completo en las acotaciones (dos veces Calisto. y una vez respectivamente Elicia., Crito. y Parmeno.) y suprime además todas las abreviaturas por suspensión dentro de los diálogos sustituyéndolas por abreviaturas por contracción formadas mediante signos especiales heredados en la letrería gótica de la escritura manuscrita medieval, abreviaturas desconocidas en las acotaciones y muy utilizadas a lo largo de todo el texto de de la obra ${ }^{31}$. Estas abreviaturas son:

28.- En e ij v:24, el cajista ha confundido la palabra "par» con la abreviatura por suspensión con que se designa a Pármeno en las acotaciones nominales (Par.).

29.- He aquí sus localizaciones en la edición de Toledo: Me. (c iij r:13,d j r:30,i ij v:11,f ij v:26), Meli. (c vj v:8), Ca. (c iiij v:14), Cali. (b v v:7), $S e<m>$. (b vj r:3,c iij v:12, c iij v:20,c iij v:28), Sem. (a vij v:31, b j r:19), Ce. (i ij v:26), Eli. (b j v:21),Par. (b v v:7, c iij v:3,e ij v:24 [errata],i v v:20), Lu. (h ij v:3), Lucre. (g vij v:17).

30.- Este caso que presentamos como ejemplo no es único. También se podrían originar confusionismo y desorientación en otros pasajes, tales como en f v r:10-30 yf v v:12-23.

31.- Pueden verse estos signos especiales de la letrería gótica en el epígrafe siguiente. 
Semp<ro $>$ nio, con contracción de $p$ por "pro», escrito con el signo especial de abreviación de la sílaba «pro»(6 veces).

$S e<m>p<r o>$ nio, con contracción de la vocal $e$ indicando la supresión de la nasal $m$ y contracción de $p$ por «pro» con su propio signo de abreviación (una vez). $p<a r>$ meno con signo especial de abreviación de la sílaba "par» (3 veces) ${ }^{32}$.

Como consecuencia de estas variaciones, el párrafo que en Toledo nos resultaba incomprensible queda más claro en la edición de Burgos:

Ce. [...] E como le fuesse necessario absentarse dexo en su lugar a melibea para. Cali. o gozo sin par. o singular oportunidad... (Burgos, e ${ }_{\mathrm{vj}}^{\mathrm{v}: 28-30}$ ).

Y perfectamente claro en las ediciones de Zaragoza y Valencia:

(Ce.) [...] Y como le fue necessario absentar se dexo en su lugar a melibea para. (Ca.) o gozo sin par / o singular

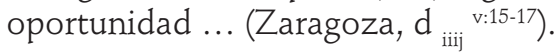

(Ce.) [...] y como le fue necessario absentar se: dexo en su lugar a Melibea para. (Ca.) o gozo sin par / o singular oportunidad ... (Valencia, d ${ }_{\mathrm{ij}}^{\mathrm{r}: 29-31}$ ).

En estas tres ediciones ya no es posible dudar — como ocurría en la de Toledo- si Calisto es el personaje de quien se habla o el personaje que habla, ni tampoco dudar si se nombra a Pármeno con abreviación por suspensión («Par.») o se hace referencia a la locución adjetiva «sin par».

En las ediciones de Zaragoza y Valencia tampoco existen abreviaturas por suspensión en los nombres de los personajes mencionados por otros, tan solo hay abreviaturas por contracción de una vocal que origina la supresión de la consonante nasal que la sigue. Así, además de las ya consignadas anteriormente, en la de Zaragoza aparecen: Sempro<n>io (una vez), Celesti $<n>a$ (11 veces) y Parme $<n>0$ (2 veces); y en la de Valencia, Ce $<n>$ turio (una vez) ${ }^{33}$.

\section{Tipos de abreviaturas en el texto de los diálogos}

En cuanto al resto de las abreviaturas incluidas en los textos, pese a que su tan crecido número - unas 5000 de media en las ediciones de la Co-

32.- Localizaciones en la edición de Burgos: Semp<ro nio (a vj v:17, b iij v:26, d j r:22, f v v:3, i v r:10, dj r:22), Se<m>p<ro>nio (k iiij v:30),p<ar>meno (f iiij 16r:22, k viij v:14).

33.- En la edición de Zaragoza: Sempro<n>io ( $\mathrm{g} v \mathrm{v}: 16$ ), Celesti< $n>a$ (b vj r:15, d iij r:2, e vj r:20, e vj r:36, e viij r:6, e viij r:9, f viij v:9, h iii v:19, h vj v:7, i vj v:20-21, i viij v:34), Parme $<n>0$ (e iij r:33, g iiij v:17). En la de Valencia: Ce<n>turio (h v r:34). 
media y unas 6000 en las ediciones de la Tragicomedia- da lugar al ahorro de 61.729 letras entre las cuatro ediciones, lo cierto es que su tipología es bastante reducida y la gran mayoría de sus formas son comunes a las cuatro ediciones, aunque no faltan casos que solamente se dan en tres o dos ediciones, incluso en una sola ${ }^{34}$. La más generalizada es la línea general de abreviación sobrescrita en determinadas letras que implica la supresión de una o más de las que le siguen y/o preceden.

Los tipos que hemos encontrado en las ediciones objeto de nuestro estudio son los siguientes:

1. Contracciones de vocales.- Son numerosísimas. Línea de abreviación sobre una vocal que precede a una consonante nasal $n$ o $m$ y que origina la supresión de ella. En el caso particular de la $i$, indica no solamente la omisión de una nasal que viene a continuación, sino también la de una nasal que la precede (LÁMINA 6).

2. Contracciones donde el signo semántico es una consonante sobre la que va la línea general de abreviación (LÁMINA 7).

3. Formas especiales.- La línea de abreviación también se utiliza a veces en palabras concretas dando lugar a abreviaciones más amplias (LÁMINA 8).

4. Otro grupo de abreviaturas se forma mediante signos especiales heredados en la letrería gótica de la escritura manuscrita medieval (LÁMINA 9).

5. Un apóstrofo detrás de la $L\left(l^{\prime}\right)$ indica la supresión de letras que pueden ir por delante o por detrás de ella (LÁMINA 10).

6. Contracciones de la preposición en con artículo determinado, demostrativo o pronombre personal. Aparece abreviada la $e$ inicial del artículo, demostrativo o pronombre, de modo que se forma una abreviatura por contracción, indicada mediante la línea general de abreviación sobre la $n$. Es una abreviatura común a Toledo, Burgos y Zaragoza que no se da en Valencia (LÁMINA 11).

7. A estos casos hay que añadir dos especiales: uno en Burgos: $q<u e>s$ $\left(e_{\text {viii }}\right.$ v:12) [que es], con la línea de abreviación sobre la q; y otro en Valencia: que $<n>\left(e_{j}{ }_{j}^{r: 10}\right)$ [que en], con la línea de abreviación sobre la $e$.

34.-En esta serie de tablas que constituyen las láminas 6, 7, 8, 9, 10 y 11, colocamos cada uno de los casos en la columna de la izquierda y a continuación un testimonio de cada edición, con lo cual nos aseguramos de que, efectivamente, tal abreviatura es utilizada en todas ellas, salvo cuando alguna de las celdas queda vacía por inexistencia de testimonio. 


\section{Conclusiones de carácter editorial}

A) Las abreviaturas por contracción utilizadas en el texto eran sin duda fácilmente interpretadas por los lectores, por eso son en general comunes a las cuatro ediciones objeto de nuestro estudio y coincidentes, además, con las que se venían utilizando en los manuscritos de la época y anteriores.

B) Como se ha visto, el uso de las abreviaturas respondía a dos necesidades distintas:

1. Permitir un ahorro estimable de papel, tinta, trabajo, tiempo, etc., $y$ en consecuencia un abaratamiento sensible del coste de la edición. Debido a esto, el cálculo del ahorro tendría que ser competencia del maestro del taller, empresario a la vez que impresor.

2. Facilitar igualmente el ajuste de las líneas e incluso de las planas, función que solo podía realizar el cajista durante su composición línea a línea.

En nuestra opinión, estas funciones estarían coordinadas. En el momento de planificar la edición mediante la elección del papel, tipos, formato, caja de escritura, etc., el maestro del taller, teniendo en cuenta el espacio que se podía ahorrar mediante el uso de las abreviaturas, determinaría el número de pliegos, completos y fracción adicional de ellos, que deberían utilizarse, y señalaría en qué puntos del original(manuscrito o edición anterior) deberían comenzar y acabar los distintos pliegos, lo que además permitía el uso simultáneo de dos o más prensas con sus correspondientes cajistas, cuestión esta última propuesta ya por otros investigadores. Y el cajista, en su composición línea a línea y plana a plana, utilizaría las abreviaturas para justificar las líneas y ajustar las planas, y, en definitiva, el pliego cuyo comienzo y final le había sido impuesto.

Puede comprenderse que tanto la labor del maestro del taller como la del cajista, resultarían mucho más fáciles si tenían a la vista una edición anterior impresa que si solo contaban con un manuscrito que incluso podía haber sido objeto de alguna corrección o expurgación de última hora, ya por parte del autor/editor, ya por parte del corrector/censor. Desde este punto de vista, puede resultar sugerente el hecho de que en la edición de Toledo existan no solamente los fallos de composición señalados por Francisco Rico, Fidel Sebastián, Jaime Moll o José Luis Canet ${ }^{35}$ y nosotros mismos- como la reducción de líneas en varias planas del cuaderno f y en la plana $b_{\text {vi }}{ }^{\mathrm{r}} \mathrm{y}$ numerosas erratas -, sino también el desbarajuste en los usos de las abreviaturas por suspensión y de los nombres completos de los personajes que hemos analizado. Son anomalías que si bien pueden deberse a una mala cuenta del original, cabe preguntarse a qué se debe esta pésima cuenta del original en una imprenta tan prestigiosa como la de 
Hagenbach y vinculada con el Arzobispo de Toledo, el futuro Cardenal Cisneros (Poyán 1861: 10-11; Norton 1997: 93-94). ¿Serían consecuencia estas anomalías de correcciones en el original manuscrito o incluso en el proceso de impresión exigidas por la eliminación o cambios a posteriori de frases o pasajes censurados, sin olvidar cierta urgencia por sacar a luz la Comedia de Calisto y Melibea? ${ }^{36}$

C) La necesidad de facilitar la lectura evitando la confusión entre las acotaciones nominales y las menciones o interpelaciones de unos personajes por otros dentro de los diálogos, llevó en la edición de Burgos a utilizar las abreviaturas por suspensión solamente en las acotaciones nominales, y los nombres completos únicamente en los diálogos, salvo las cinco excepciones ya señaladas anteriormente. Las ediciones de Zaragoza y Valencia perfeccionan la distinción colocando entre paréntesis las acotaciones nominales escritas en abreviación por suspensión.

En cambio la edición de Toledo utiliza casi indistintamente en ambos casos tanto las abreviaturas por suspensión como los nombres completos, provocando la confusión entre unos y otros en 150 ocasiones. Esto supone un paso atrás prácticamente inconcebible si la edición de Burgos hubiera sido anterior a la de Toledo, siendo, por el contrario, completamente lógico que aquella hubiera corregido los defectos de ésta en esta cuestión.

D) Lo expuesto permite deducir que la edición de Toledo no pudo colacionar su fuente con la edición de Burgos, siendo, por consiguiente, anterior a ésta, o lo que es lo mismo, la edición de Toledo tuvo que ser la más antigua de todas las existentes y muy probablemente teniendo como original de imprenta un manuscrito.

Y para finalizar, permítasenos una observación y una pregunta. Se sabe que la edición de una obra requería invertir un gran capital que se había de recuperar vendiéndola, que los libreros e impresores estaban atentos a lo que se publicaba en otras imprentas y que disponían de cauces de distribución de sus mercancías en otras ciudades, y que Burgos y Toledo formaban un eje comercial importante ${ }^{37}$. Teniendo en cuenta esto, ¿es normal que si la lujosa edición de Fadrique de Basilea hubiera estado comercializada no hubiera llegado un ejemplar a la imprenta de Toledo

36.- Para las correcciones en el original de imprenta, cuya presencia en los márgenes y entre líneas, tachaduras, etc. dificultarían la cuenta del original y su traslado al impreso, es ilustrativo el artículo de Pablo Andrés Escapada et alii (2000). En cuanto a la censura, Fermín de los Reyes Gómez (2000: 94, n. 32) ve en el colofón rimado de Alonso de Proaza un testimonio de censura anterior a la Pragmática de los Reyes Católicos de 1502, y Antonio Sánchez SánchezSerrano y Remedios Prieto (2011: 120-122) postulan que el censor fue Alonso de Proaza.

37.- En relación con la actividad mercantil de distribución de libros, son de interés los estudios de Pedraza Gracia (2008: 295-335) y José Luis Canet (2009: 62 -70 especialmente en lo relativo al sistema comercial). 
y no hubiera sido por lo menos ojeado por el maestro del taller, cajistas, corrector de la imprenta, etc. orientándose y evitando así tantos errores?

\section{Bibliogafía citada}

Andrés Escapa, Pablo; Delgado Pascual, Elena; Domingo Malvadi, Arantxa, y Rodríguez MontederRAmo, José Luis (2000), «El original de imprenta", en Imprenta y crítica textual en el Siglo de Oro. Estudios publicados bajo la dirección de Francisco Rico, ed. de Pablo Andrés Escapa y Sonia Garza, Valladolid, Centro para la Edición de los Clásicos Españoles, Universidad de Valladolid, pp. 29-64.

Bernaldo de Quirós, José Antonio (2010), Comedia de Calisto y Melibea. Hacia La Celestina anterior a Fernando de Rojas, Madrid, Manuscritos.

- (2012), «Efectos provocados en la Comedia de Calisto y Melibea por las adiciones primeras. Una clasificación», Etiópicas, 8, pp. 172-199.

BotTA, Patrizia (1999), «El texto de La Celestina en la edición de Valencia, 1514», en Tragicomedia de Calisto y Melibea (Valencia, Juan Joffre, 1514). Estudios y edición paleográfica y facsimilar, eds. Nicasio Salvador Miguel y Santiago López-Ríos, Valencia, Institució Alfons el Magnànim, vol. I, pp. 17-29.

Canet Vallés, José Luis (1999), "Alonso de Proaza», en Tragicomedia de Calisto y Melibea (Valencia, Juan Joffre, 1514). Estudios y edición paleográfica y facsimilar, eds. Nicasio Salvador Miguel y Santiago López-Ríos, Valencia, Institució Alfons el Magnànim, vol. I, pp. 31-38.

- (2007), "Celestina: 'sic et non'. ¿Libro escolar-universitario?», Celestinesca, 31, pp. 23-58.

- (2009), "Algunas reflexiones sobre el proceso de edición en el siglo XVI y la bibliografía textual», Edad de Oro, xxviII, pp. 59-72.

- (2011), Comedia de Calisto y Melibea. Edición crítica, introducción y notas, Valencia, Universitat de València, Textos Parnaseo.

Cantalapiedra Erostarbe, Fernando (2000), Anónimo / Fernando de Rojas.

TragiComedia de Calisto y Melibea. I: La Celestina y su autoría. II: Edición crítica. III: Floresta celestinesca. Kassel: Reichenberger.

- (2001), "Sentencias petrarquistas y adiciones a la Tragicomedia de Calisto y Melibea", en Tras los pasos de "La Celestina", ed. de Patrizia Botta, Fernando Cantalapiedra, Kurt Reichenberger y Joseph T. Snow, Kassel, Reichenberger, pp. 55-154.

- (2011), «Fue tanto breve quanto muy sutil. Los paratextos de La Celestina», EHumanista, 19, pp. 20-78. 
Comedia de Calisto y Melibea [1499-1502?], Burgos, Fadrique de Basilea. Edición facsimilar de Archer M. Huntington, New York, Hispanic Society of America, 1909 (Reimpresa en 1970)

Comedia de Calisto y Melibea [1499-1502?], Burgos, Fadrique de Basilea. Edición facsimilar de Emilio de Miguel Martínez, Salamanca, Junta de Castilla y León-Caja Duero, Ediciones Universidad de Salamanca, 1999, 2 vols.

Comedia de Calisto y Melibea. Facsímil de la edición de Toledo 1500, ed. Daniel Poyán Díaz, Cologny-Ginebra, Bibliotheca Bodmeriana, 1961.

Di Camillo, Ottavio (2005a), "Pesquisas indiciarias sobre el incunable acéfalo de la Comedia de Burgos», en Filologia dei testi a stampa (Area Iberica), a cura di Patrizia Botta), Modena, Mucchi Editore, pp. 75-96.

- (2005b), "The Burgos comedia in the printed tradition of La Celestina: A Reassessment", en La Celestina 1499-1999. Selected Papers from the International Congress in commemoration of the Quincentennial Anniversary of La Celestina, New York,November 17-19, 1999, ed. de Ottavio Di Camillo y John O'Neill, New York, Hispanic Seminary of Medieval Studies, pp. 235-359.

Fernández Valladares, Mercedes (2005), La imprenta en Burgos (15011600), Madrid, Arco/Libros, 2 vols.

García Valdecasas, José Guillermo (2000), La adulteración de "La Celestina», Madrid, Castalia.

Garza Merino, Sonia (2000), «La cuenta del original», en Imprenta y crítica textual en el Siglo de Oro. Estudios publicados bajo la dirección de Francisco Rico, al cuidado de Pablo Andrés y Sonia Garza, Valladolid, Centro para la Edición de los Clásicos Españoles, Universidad de Valladolid, pp. 65-95.

INFANTES, Víctor (2007), «El laberinto cronológico y editorial de las primitivas impresiones de Celestina (1497-1514). Con una Marginalia bibligraphica al cabo", en Actas del Simposio Internacional "1502-2002: Five Hundred Years of Fernando de Rojas' "Tragicomedia de Calisto y Melibea": (18-19 de octubre de 2002, Departamento de Español y Portugués, Indiana University, Bloomington), ed. Juan Carlos Conde, New York, Hispanic Seminary of Medieval Studies, 2007, pp. 3- 87.

- (2010), La trama impresa de Celestina. Ediciones, libros y autógrafos de Fernando de Rojas, Madrid, Visor Libros.

Marciales, Miguel (ed.) (1985), Celestina. Tragicomedia de Calisto y Melibea. Fernando de Rojas. Introducción y edición crítica. Al cuidado de Brian Dutton y Joseph T. Snow. Urbana y Chicago, University of Illinois Press, 2 vols. MARTín ABAD, Julián(coord.) (1999), Un volumen facticio de raros post-incunables españoles, Toledo, Antonio Pareja Editor.

- (2001), Post-incunables ibéricos, Madrid, Ollero \& Ramos Editores.

MCKERROW, Ronald B. (1998), Introducción a la Bibliografía material, Madrid, Arco/Libros, col. Instrumenta Bibliologica. 
MCPheeteers, D. W. (1961), El humanista español Alonso de Proaza, Madrid, Castalia.

Miguel Martínez, Emilio de. Ver Comedia de Calisto y Melibea (14991502?).

Moll RoavetA, Jaime (2000), «Breves consideraciones heterodoxas sobre las primera ediciones de La Celestina», Voz y Letra. Revista de Literatura, XI, I, pp. 21-25.

-------(2011), Problemas bibliográficos del libro del Siglo de Oro, Madrid, Arco/Libros, col. Instrumenta Bibliologica.

Montañés Fontela, Luis (1973), "El incunable toledano de la Comedia de Calisto y Melibea (La Celestina)", Anales toledanos, viII, pp. 131-179.

NORTON, Frederik J. [1966] (1997), La imprenta en España. 1501-1520. Traducción de Daniel Martín Arguedas. Edición anotada por Julián Martín Abad, Madrid, Ollero \& Ramos Editores.

Paolini, Devid (2011), Reseña de José Luis Canet Vallés (ed.), Comedia de Calisto y Melibea, edición crítica, introducción y notas, Celestinesca, 35, pp., 161-167.

Pedraza Gracia, Manuel José (2003), «La elaboración del libro», en Manuel José Pedraza Gracia, Yolanda Clemente San Román y Fermín de los Reyes Gómez, El libro antiguo, Madrid, Síntesis, Biblioteconomía y Documentación, pp. 49-133.

- (2008), El libro español del Renacimiento. La "vida" del libro en las fuentes documentales contemporáneas, Madrid, Arco/Libros, col. Instrumenta Bibliologica.

Poyán Díaz, Daniel (ed.) (1961), Comedia de Calisto y Melibea, Toledo, Pedro Hagenbach, 1500. Edición facsímil, Cologny-Genève, Bibliotheca Bodmeriana.

Prieto de la IGlesia, Remedios2000), "Reflexiones sobre el íncipit y la portada de las ediciones de la Comedia de Calisto y Melibea y el Manuscrito de Palacio", Celestinesca, 24, pp. 57-68.

- (2001), "La portada de las ediciones de la Comedia y el Manuscrito 1520 de Palacio: evolución textual de La Celestina», en Felipe B. Pedraza Jiménez, Rafael González Cañal y Gema Gómez Rubio, eds., La Celestina v Centenario (1499-1999). Actas del Congreso Internacional Salamanca - Talavera de la Reina-Toledo-La Puebla de Montalbán, 27 de septiembre-1 de octubre de 1999, Cuenca, Universidad de Castilla-La Mancha / Cortes de Castilla-La Mancha, pp. 283-291.

- Ver Sánchez Sánchez-Serrano, Antonio, y Prieto de la Iglesia, Remedios.

Reyes Gómez, Fermín de los (2000), El libro en España y América. Legislación y Censura (siglos XV-XVIII), Madrid, Arco/Libros, col. Instrumenta Bibliologica, 2 vols.

Rico, Francisco (2000), "Crítica textual y transmisión impresa (Para la edición de La Celestina)", en Imprenta y crítica textual en el Siglo de Oro. 
Estudios publicados bajo la dirección de Francisco Rico, al cuidado de Pablo Andrés y Sonia Garza, Valladolid, Centro para la Edición de los Clásicos Españoles, Universidad de Valladolid, pp. 223-241.

Salvador Miguel, Nicasio (1999), "Fernando de Rojas» en Tragicomedia de Calisto y Melibea (Valencia, Juan Joffre, 1514). Estudios y edición paleográfica y facsimilar, eds. Nicasio Salvador Miguel y Santiago López-Ríos, Valencia, Institució Alfons el Magnànim, vol. I, pp. 7-15.

Salvador Miguel, Nicasio, y López Ríos, Santiago. Ver Tragicomedia de Calisto y Melibea (Valencia, Juan Joffre, 1514).

Sánchez Prieto, Ana Belén (2001), "Las abreviaturas como indicadores de hábitos de lecto-escritura», Norba. Revista de Historia, 15, pp. 159-168.

Sánchez SÁnchez-Serrano, Antonio [1985] (1987), Mensaje de La Celestina. Análisis de un proceso de comunicación diferida (Departamento de Lingüística y Literatura, Facultad de Ciencias de la Información. Premio Extraordinario de Doctorado correspondiente al curso académico 1984-1985). Madrid, Universidad Complutense, col. Tesis Doctorales, $n^{\circ}$ 10/87.

- (2001), "Otro punto de vista sobre el Manuscrito de Palacio Ms 1520», en Felipe B. Pedraza Jiménez, Rafael González Cañal y Gema Gómez Rubio, eds., La Celestina V Centenario (1499-1999). Actas del Congreso Internacional Salamanca-Talavera de la Reina-Toledo-La Puebla de Montalbán, 27 de septiembre-1 de octubre de 1999, Cuenca, Universidad de Castilla-La Mancha / Cortes de Castilla-La Mancha, pp. 273-281.

- y Prieto de la Iglesia, Remedios (1991), Fernando de Rojas y La Celestina, Barcelona, Teide, col. El escritor y su literatura.

- (2009), "Sobre la 'composición' de la Celestina y su anónimo 'auctor'», Celestinesca, 33, pp. 143-171.

- (2011), "'Auctor', 'Autor' y otros problemas semánticos concernientes a la autoría, gestación y ediciones de la Celestina», Celestinesca, 35, pp. 85-136.

Sebastián Mediavilla, Fidel (2003), "Las primeras ediciones de La Celestina y su puntuación", Boletín de la Real Academia Española, tomo LXXXIII, cuaderno CCLCCCVII, pp. 113-135.

Serés, Guillermo (2000), "Primeros textos y fortuna editorial (siglos XVI y XVII)», en Fernando de Rojas (y "Antiguo Autor»). La Celestina. Tragicomedia de Calisto y Melibea, edición y estudios de Francisco J. Lobera, Guillermo Serés, Paloma Díaz-Mas, Carlos Mota, Íñigo Arzálluz y Francisco Rico, Barcelona, Crítica, pp. lxxii-xci. Reproducido en la $2^{\mathrm{a}}$ e d i ción (2011), pp. 382-401.

Snow, Joseph T. (1990), «La iconografía de tres Celestinas tempranas (Burgos 1499, Valencia 1514, Sevilla 1518)", en Arcadia: Estudios y textos dedicados a Francisco López Estrada. Dicenda: Cuadernos de Filología Hispánica, 6, 1987 [1990], pp. 255-277.

- (2005), "Imágenes de la lectura / lectura de las imágenes: el caso de la Comedia burgalesa por Fadrique de Basilea», en Patrizia Botta (coord.), 
Filologia dei testi a stampa (Area Iberica), Modena, Mucchi Editore, pp. 111-129.

Snow, Joseph T. (2005-2006), "La problemática autoría de Celestina», Íncipit, no 25-26, pp. 537-561.

TRAGICOMEDIA de Calisto y Melibea (1507), Zaragoza, Jorge Coci. Edición facsimilar y estudios coordinados por Julián Martín Abad, en Un volumen facticio de raros post-incunables españoles, Toledo, Antonio Pareja Editor, 1999, 2 vols.

TRAGICOMEDIA de Calisto y Melibea (1514). Edición facsimilar, Madrid, Espasa-Calpe, 1975.

TRAGICOMEDIA de Calisto y Melibea (1514). Edición facsimilar, Barcelona, Círculo del Bibliófilo, 1977.

TRAGICOMEDIA de Calisto y Melibea (Valencia, Juan Joffre, 1514). Estudios y edición paleográfica y facsimilar, dirigida por Nicasio Salvador Miguel y Santiago López-Ríos, Valencia, Institució Alfons el Magnànim, 1999, 2 vols.

Westerveld, Govert (2005-2009), Los tres autores de "La Celestina»: el judeoconverso Juan Ramirez de Lucena, sus hijos Fernando de Rojas (Lucena) y Juan del Encina, Blanca, Academia de Estudios Humanísticos de Blanca, 4 vols. 


\section{LÁMINA 1}

I baser a mi inmerito tanta merces ā vcr te alcancaffe: en tan conuenientelugar āmi fecreto ooloz manifeit ar te puoieffe: fin ouboa encōparablemente es mayoz tal ga/ lardonā el feruicio:facrificio:denocion: $z$ obras pias $\bar{q}$ poz eftelugar alcáçar tengo yo a dios ofrelcioo t Thi otro poder mi volītad bumana pueoc cōplir:quiē vionenefta víoacuerpoglozíficado de ningun bəöbze como agoza el mío:"Doz cierto los gloriofos fantos que fe delepran enla vifion diuína no gozan mas que yoagoraenel a catamiet to tuyo. AD as o trifte que en efto ocferimos:que ellos pura mente fe gllozifican fin temoz oe caer oe tal bienauenturā ça: $z$ yo nifto me alegro con recelo del elquíno tozmento que tuabrencia me ba de caufar, anse.poz grano pzenio tienes cfte califto. La.tengolo pos tanto en verbad que fi dios me dieffe enel cielo lafilla fobze fus fantos no loter/ nia poz tanta felicioad, ODe, pues abninas ygual galar/ oon te oare yo fi perfeneras. jas mias que inoignamente tan gran palabza baueps op\% Do. aDe. mas delauenturadas oe queme acabes de opr: pozque la paga fera tan fiera qual la merec tuloco atreui miento y cl intento de tus palabzas califtos fepoo:de in genío de tal böbze como tubauer de falír para fe poer en la virtus oetal muger como yo. Elete vete de ap tozpe: $\tilde{q}$ no pucoe imi pacienciatollerar que aya fubjoocti cozaçon bumano conmigo el illicito amoz comunicar fudeleyte. Ea.yre comoaquel contra quie folamente laaouerfa foz tuna pone fu eftudio con ooio cruel. Gompzonio: [empzo niv: fempzonio. donde eftaefte maloito: Sem,aqui eftop feñoz curanoo de eftos cauallos. Ea.pues como fales de lafala. Semrabatiofe el girifalte 7 vine le endereçarenel 30 alcanoarg. Es.afilos oiablos te ganen: afi poz infoztuy nio arrebataso perescas/o perpetuo intollerable tozme 
LÁMINA 2

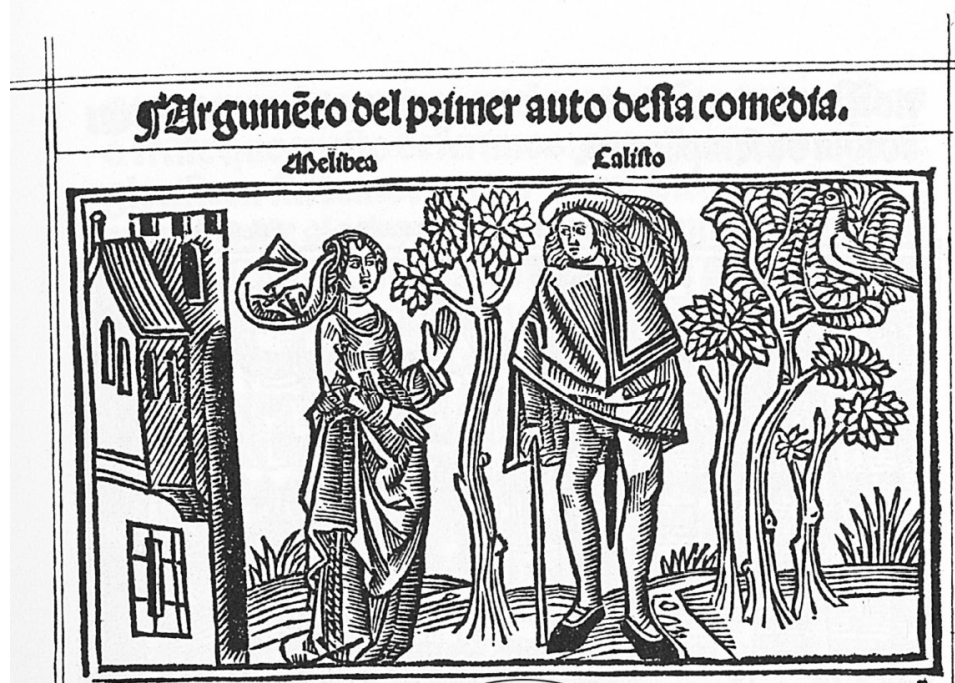

17 Ihntrãoor Califtonna buerta empos 8 - vn falcon fuy o fallo y a d Delibea oe cu 17. 20 ainoz pzefo comécole de bablar: oela 1. qual rigozofaméte oéŕpedioo: fue para ir cafa inup fanguftiado bablo con un criad fupo llantao ofempzonto el qual defpues de inuchas rajones le enoerecco a vna vieja llannos cele ftina:en cung cafa cenia el meefnio criaoo ona enanto

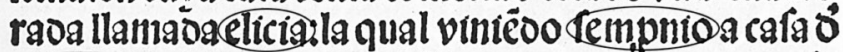
celeftinaroöel negocio oe fil amo tenia a otro confis gollamado crito:al qual efcondierō. Lintre tanto q̋ ¿empzonioefta negociāoo conceleftina: califtoefta razonanoo có otro cría o fiuy o poz nöbzeparimenos el qual rasonamiêtro oura fátta ă llega Esempzonio zceleftina a cafa de califto. armenofue conolcioo oeceleftina:la qual unucbo le oize oelos fecbos $z \mathrm{cos}$

a 1 .

Edición de Burgos, $a_{j}{ }^{R}$

Uso de mayúsculas o minúsculas en función del espacio disponible 


\section{LÁMINA 3}

Se transcriben en cursiva las acotaciones nominales que siguen la regla general (abreviaturas por suspensión) y las que van abreviadas por contracción + suspensión. Las excepciones con nombre completo se transcriben en cursiva negrita. A cada acotación de las ediciones de Burgos y Toledo les sigue un número que indica la frecuencia.

\begin{tabular}{|c|c|c|c|c|}
\hline & TOLEDO & BURGOS & ZARAGOZA & VALENCIA \\
\hline Melibea & $\begin{array}{l}\text { Me. (99) } \\
\text { Meli. (4) } \\
\text { Melibea (1) }\end{array}$ & $\begin{array}{l}\text { Me. }(94) \\
\text { Meli. }(10)\end{array}$ & $\begin{array}{l}\text { (Me.) (Me) } \\
\text { (Meli.) }\end{array}$ & $(M e).(M e)$ \\
\hline Calisto & $\begin{array}{l}\text { Ca. (199) } \\
\text { Cali. (5) } \\
\text { Ce. (2) [erratas] } \\
\text { Cae. (1) [errata] } \\
\text { Calisto. (2) } \\
\text { Calisto (4) } \\
\end{array}$ & $\begin{array}{l}\text { Ca. (186) } \\
\text { Cali. (18) } \\
\text { Cal. (6) } \\
\text { Ca (1) } \\
\text { Calisto. (2) }\end{array}$ & $\begin{array}{l}\text { (Ca.) (Ca) } \\
\text { (Cali.) }\end{array}$ & $\begin{array}{l}(\text { Ca.) (Ca) } \\
(C e .) \text { [errata] }\end{array}$ \\
\hline Sempronio & $\begin{array}{l}\text { Sem. (107) } \\
\text { Sem: (1) [errata] } \\
\text { Se }<m>\text {. (94) } \\
\text { Sempronio. (1) } \\
\text { Sempronio: (2) } \\
\text { Sempronio (6) }\end{array}$ & $\begin{array}{l}\text { Sem. (119) } \\
\text { Semp. (2) } \\
\text { Sempro. (1) } \\
\text { Sen. (6) [falsas } \\
\text { erratas] } \\
\text { Se }<m>\text {. (82) } \\
\text { Se }<m>\text { (1) }\end{array}$ & 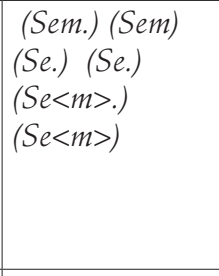 & $\begin{array}{l}\left(S_{e}<m>.\right) \\
\left(S_{e m}\right) \\
\left(S_{e}<m>\right)\end{array}$ \\
\hline Celestina & $\begin{array}{l}\text { Ce. (219) } \\
\text { Cele. (8) } \\
\text { Celest. (1) } \\
\text { Celi. (2) } \\
\text { [erratas] } \\
\text { Celestina. (16) } \\
\text { Celicia. (1) } \\
\text { [errata] } \\
\text { Celestina: (2) } \\
\text { Celestinal (1) } \\
\text { Celestina (22) }\end{array}$ & $\begin{array}{l}\text { Ce. (210) } \\
\text { Cel. (21) } \\
\text { Cele. (41) }\end{array}$ & $\begin{array}{l}(\mathrm{Ce} .)(\mathrm{Ce}) \\
\text { (Cele.) }\end{array}$ & $\begin{array}{l}(\mathrm{Ce} .)(\mathrm{Ce}) \\
\text { Ce.) [falta el } \\
\text { paréntesis de } \\
\text { apertura] } \\
(\text { Ca. }) \text { [errata] }\end{array}$ \\
\hline Elicia & $\begin{array}{l}\text { Eli. (29) } \\
\text { Elicia. (2) } \\
\text { Elisa. (3) } \\
\text { [erratas] } \\
\text { Elicia (1) } \\
\text { Elisa (3) } \\
\text { [erratas] }\end{array}$ & $\begin{array}{l}\text { Eli. (37) } \\
\text { Elicia. (1) }\end{array}$ & (Eli.) (Eli) & (Eli.) \\
\hline Crito & Crito. (1) & Crito. (1) & (Cri.) & (Cri.) \\
\hline
\end{tabular}




\begin{tabular}{|c|c|c|c|c|}
\hline Pármeno & $\begin{array}{l}\text { Par. (133) } \\
\text { Parmeno. (11) } \\
\text { Parmeno: (3) } \\
\text { Parmeno (11) } \\
\text { Parmenio (1) } \\
\text { [errata] } \\
\text { parmeno. (1) }\end{array}$ & $\begin{array}{l}\text { Par. (157) } \\
\text { Parme. (2) } \\
\text { Parmeno. (1) }\end{array}$ & $\begin{array}{l}\text { (Par.) (Par) } \\
(\text { Pa. })\end{array}$ & (Par.) (Par) \\
\hline Lucrecia & Lu. (38) & $\begin{array}{l}\text { Lu. (37) } \\
\text { Lucre. (1) }\end{array}$ & (Lu.) (Lu) & $(L u) \quad.(L u)$ \\
\hline Alisa & Ali. (18) & Ali. (18) & $\begin{array}{l}\text { (Ali.) (Ali) } \\
\text { (Alisa.) }\end{array}$ & (Ali.) \\
\hline Areúsa & $\begin{array}{l}\text { Are. (7) } \\
\text { Areu. (1) } \\
\text { Areusa. (16) } \\
\text { Areusa: (1) } \\
\text { Areusa (8) } \\
\text { [Omitido: 1] }\end{array}$ & $\begin{array}{l}\text { Are. (26) } \\
\text { Areu. (8) }\end{array}$ & (Are.) (Are) & $\begin{array}{l}\text { (Areu.) (Are) } \\
\text { (Are.) (Areu) }\end{array}$ \\
\hline Pleberio & Ple. (13) & $\begin{array}{l}\text { Ple. (12) } \\
\text { Plebe. (1) }\end{array}$ & (Ple.) (Ple) & (Ple.) \\
\hline Tristán & $\begin{array}{l}\text { Trist. (6) } \\
\text { Tristan: (2) } \\
\text { Tristan (6) } \\
\end{array}$ & Trist. (14) & (Tri.) (Tri) & (Tri.) \\
\hline Sosia & $\begin{array}{l}\text { So. }(16) \\
\text { Sosia (1) } \\
\text { [Omitido: 1] }\end{array}$ & So. (18) & (So.) (So) & (So.) (So) \\
\hline Centurio & & & $\begin{array}{l}(\mathrm{Ce}<n>.) \quad(\mathrm{Cen} .) \\
(\mathrm{Cen})(\mathrm{Ce}<n>)\end{array}$ & $\begin{array}{l}(\mathrm{Ce}<n>.) \\
(\mathrm{Cen} .) \\
(\mathrm{Ce}<n>)\end{array}$ \\
\hline $\begin{array}{l}\text { Total de } \\
\text { excepcio- } \\
\text { nes con el } \\
\text { nombre } \\
\text { completo }\end{array}$ & 129 & 5 & 1 & 0 \\
\hline
\end{tabular}




\section{LÁMINA 4}

cla sellugar es pooer of de apartar el entreñable so moz:el fuego ă efta en ini coraçon.0o yo vo comigo vas:comigo eftas:no reaflijas ni me atozmêtes mar deloã vo be padeciso:mas di que pafios fuenā arr ba. IEli.quie: vn ni enanosaco. Dem.pues creolo: 5

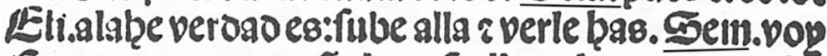
[Le.anoa acs dera effa loca:q̄ ella es liuiana: $r$ turba oa oe tuabrencia: facas la agoza oe fefo: Dira mill los curas: vé z fablentos no deremos paffar el tiêpo en baloe. Dê. pues quien efta arriba. Ĺe. äres lo faber. 10 Sem.g̀ero. Le.vna moca que me encomédo vn frap le. De.que fraple. LEe.no lo pzocures. Seentpor mi vi oa madeze âfräule. Le.pozfias: el nuiniftro el gozoo. Gem1.o defaueturada zq carga épera. Le. tooo lo leuanos:pocas mataouras as tu vifto enla barriga 15 Gem.miataouras no: mas petreras fi. Le.ap burlas D02. Eelli.oera fi fop burlada a mueftra me la. LEli.

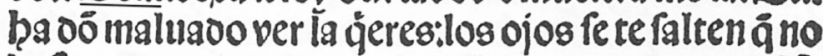
bafta a ti vna ni otra anos veela z oeta a mi para fiê. pze. Sem.calla dios mio:z enoias te. que nila q́ero 20 veer a ella ni a muger nafcioa. OAmi maoze quiero fa

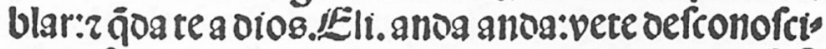

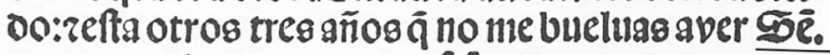
Ingoze unia bien ternas confiäca z creeras que note burlo. Toma el inarto z vamos:que poz el camino fa 25 bzas lo ä fi gqui the taragfe en oeżirte: empeoiria tu „puecho r el nitio. Lel. vamog:elicia queos teg oios: cierra la puerta:a oios pareoes. Ge111. 0 111903e nimta: todas cofas nexadsg a pte:folamête fe atenta: z puna gina enlo ñ te oikere: zno derranes tu penfamiêto 30

$$
\text { Edición de Burgos, } a_{v i j}{ }^{v}
$$

Alteración de la ortografía con el fin de justificar la linea

El cajista solo podia recurrir al cambio de la M por la N para ajustar la linea 12. Los dos puntos (..) con que termina la replica anterior de Sempronio son inamovibles: uno cierra sus palabras y el 


\section{LÁMINA 5}

Se transcriben en negrita y cursiva los nombres abreviados excepcionalmente por suspensión, y simplemente en cursiva los abreviados por contracción. Los números entre paréntesis indican las frecuencias y las celdas vacías la inexistencia de nombres con abreviaturas.

\begin{tabular}{|c|c|c|c|c|}
\hline & TOLEDO & BURGOS & ZARAGOZA & VALENCIA \\
\hline Melibea & $\begin{array}{l}\text { Me. (4 ) } \\
\text { Meli. (1) }\end{array}$ & & & \\
\hline Calisto & $\begin{array}{l}\text { Ca. (1) } \\
\text { Cali. (1) }\end{array}$ & & & \\
\hline Sempronio & $\begin{array}{l}\text { Se<m>pronio } \\
(58) \\
\text { Se }<m>\text {. (4) } \\
\text { Sem. (2) }\end{array}$ & $\begin{array}{l}\text { Se }<m>\text { pronio (4) } \\
\text { Semp }<\text { ro }>\text { nio (6) } \\
\text { Se }<m>\text { p }<\text { ro }>\text { nio } \\
\text { (1) }\end{array}$ & $\begin{array}{l}\text { Se }<m>\text { pronio } \\
(24) \\
\text { Sempro }<n>\text { io }(1)\end{array}$ & $\begin{array}{l}\text { Se }<m>\text { pronio } \\
(20)\end{array}$ \\
\hline Celestina & Ce. (1) & & Celesti< $n>a(11)$ & \\
\hline Elicia & Eli. (1) & & & \\
\hline \multicolumn{5}{|l|}{ Crito } \\
\hline Pármeno & Par. $(3+1)$ & $p<a r>m e n o(3)$ & Parme $<n>0$ (2) & \\
\hline Lucrecia & $\begin{array}{l}\text { Lu. (1) } \\
\text { Lucre. (1) }\end{array}$ & & & \\
\hline \multicolumn{5}{|l|}{ Alisa } \\
\hline \multicolumn{5}{|l|}{ Areúsa } \\
\hline \multicolumn{5}{|l|}{ Pleberio } \\
\hline Tristán & Trista $<n>(1)$ & & Trista $<n>(4)$ & Trista $<n>(3)$ \\
\hline \multicolumn{5}{|l|}{ Sosia } \\
\hline Centurio & $\begin{array}{l}\text { [No existe el } \\
\text { personaje] }\end{array}$ & $\begin{array}{l}\text { [No existe el } \\
\text { personaje] }\end{array}$ & & Ce $<n>$ turio (1) \\
\hline Traso & $\begin{array}{l}\text { [No existe el } \\
\text { personaje] }\end{array}$ & $\begin{array}{l}\text { [No existe el } \\
\text { personaje] }\end{array}$ & & \\
\hline $\begin{array}{l}\text { Total de } \\
\text { excep- } \\
\text { ciones } \\
\text { mediante } \\
\text { abrevia- } \\
\text { turas por } \\
\text { suspensión }\end{array}$ & 21 & 0 & 0 & 0 \\
\hline
\end{tabular}

Abreviaturas excepcionales en los nombres de los personajes integrados en los diálogos. 


\section{LÁMINA 6}

\begin{tabular}{|c|c|c|c|c|}
\hline & Toledo & Burgos & Zaragoza & Valencia \\
\hline$\overline{\mathrm{a}}=$ [an] & tāto & Entrādo & alcāçasse & grādeza \\
\hline$\overline{\mathrm{a}}=[\mathrm{am}]$ & estābre & preābulos & cābios & alābiques \\
\hline$\overline{\mathrm{e}}=[\mathrm{en}]$ & induciēdole & argumēto & conueniēte & comēçole \\
\hline$\overline{\mathrm{e}}=[\mathrm{em}]$ & Sēpronio & tiēpo & destēplado & tēplara \\
\hline $\bar{T}=[\mathrm{in}]$ & hīcha & itrinseco & vezīdad & prīcipal \\
\hline $\bar{T}=[\mathrm{im}]$ & Tperuio & Tmerito & anīales & Tpossible \\
\hline$T=[$ nim $]$ & aĩales & ā̄a & aīa & aĩosos \\
\hline$\overline{0}=[o n]$ & cō & escondierō & galardō & cōsigo \\
\hline$\overline{\mathrm{o}}=[\mathrm{om}]$ & nōbre & encōparablemente & hōbre & cōparacion \\
\hline$\overline{\mathrm{u}}=[\mathrm{un}]$ & volūtad & nūca & segū & mūdo \\
\hline $\bar{u}=[u m]$ & alūbre & cūpliendo & costūbres & hūana \\
\hline
\end{tabular}

Abreviaturas por contracción de vocales

\section{LÁMINA 7}

\begin{tabular}{|c|c|c|c|c|}
\hline & Toledo & Burgos & Zaragoza & Valencia \\
\hline$\overline{\mathrm{p}}=[\mathrm{pre}]$ & $\bar{p}$ cededète & 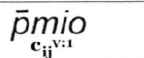 & $\bar{p}$ sente & $\bar{p} S_{\mathbf{a}_{i i j} \mathbf{v i}_{31}}$ \\
\hline $\bar{q}=$ [que] & $\bar{q}_{\mathrm{a}_{\mathrm{iij}}^{\mathrm{R}: 21}}$ & 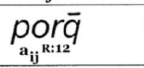 & $\left.a \bar{q}\right|_{a_{v} v: 11}$ & 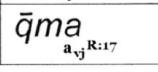 \\
\hline
\end{tabular}

Contracciones donde el signo semántico es una consonante

\section{LAMINA 8}

\begin{tabular}{|c|c|c|c|c|}
\hline & Toledo & Burgos & Zaragoza & Valencia \\
\hline tiempo & ------- & $t \overline{p_{\mathbf{b}_{\mathbf{b}} \mathbf{R}: 30}}$ & $t \bar{p} O_{\mathrm{d}_{\mathrm{i}} \mathrm{v}: 22}$ & |------- \\
\hline gracia: s. y pl. & $\begin{array}{l}g \bar{r} a \\
\mathbf{a}_{v i j} v:=2\end{array}$ & $\underset{c_{v_{v} v_{i}: 7}}{g \overline{r a}}$ & $g \overline{r a}$. & $\underset{\mathbf{a}_{\text {viji }}}{g \bar{r}: 22}$ \\
\hline nuestro, a, os, as & $n_{\mathbf{c}_{i j}:=26} \bar{r} O$ & 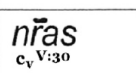 & $n \bar{r} a_{\mathbf{b}_{\mathbf{v}} \mathbf{v}: 18}$ & $\underset{\mathbf{d}_{\mathbf{j}} \mathbf{v}^{: 3}}{\bar{r}}$ \\
\hline vuestro, a, os, as & $\overrightarrow{V \overrightarrow{r O}} \mathbf{f}_{j}^{R: 12}$ & $v \bar{r}_{\mathbf{h}_{\text {iin }}} S_{\mathrm{R}: 1}$ & $\bar{r}_{\mathrm{f}_{\mathrm{ij}} \mathbf{i}: 27}$ & $\operatorname{vras}_{\mathbf{e}_{\mathrm{vj}} \mathrm{v}_{\mathrm{i} 222}}$ \\
\hline
\end{tabular}

Formas especiales 
LÁMINA 9

\begin{tabular}{|c|c|c|c|c|}
\hline & Toledo & Burgos & Zaragoza & Valencia \\
\hline $\mathrm{p}=$ [par] & $\underset{b_{b_{i j}: \geq 6}}{\operatorname{aptada}}$ & 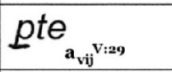 & incōpableme $_{\mathbf{a}_{\mathbf{v}} \text { :R29 }} \bar{e}$ ète & $p a_{\mathrm{b}_{\mathrm{j}}^{\mathrm{v}: 18}}$ \\
\hline $\mathrm{p}=$ [per] & 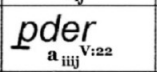 & $p o_{\mathbf{a}_{\mathbf{v}}: \text { :ig }}$ & pfecta $_{\mathrm{a}_{\mathrm{v}} \mathrm{R}: 25}$ & $\underset{\mathbf{a}_{\mathbf{v}} \mathbf{R}: 33}{\text { pseusas }}$ \\
\hline$p=$ [pro] & 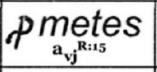 & $\underset{\mathbf{a}_{\mathbf{v} j} \mathbf{v}: 7}{\operatorname{semp}}$ & ppria ${ }_{\mathbf{c}_{\mathbf{v i j i}}}$ & pcuraron \\
\hline$q=$ [qui] & $\underset{a_{v i j}: 1 / 3}{z e r o}$ & 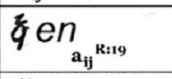 & 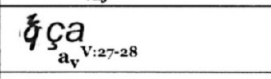 & 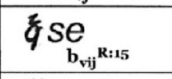 \\
\hline$\ddot{q}=$ [qua] & $\ddot{q} l_{\mathrm{a}_{i \mathrm{ij}} \mathrm{R}: 25}$ & $\ddot{q} n d \mathrm{a}_{\mathrm{a}_{\mathrm{vj}}^{\mathrm{R}: 22}}$ & $\ddot{q} \operatorname{les}_{\mathbf{a}_{v i j}}$ & 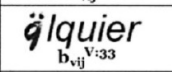 \\
\hline$\partial^{\prime}=[\mathrm{de}]$ & 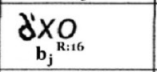 & 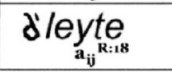 & $\underset{\mathbf{a}_{\mathrm{v}} \text { vits }}{\text { d'sastrada }}$ & 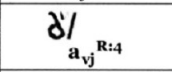 \\
\hline$x=$ [ver] & $\underset{i_{i j}=1+s}{d a d}$ & 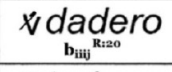 & vdaderos & 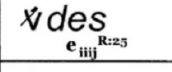 \\
\hline$\Downarrow=[$ vir $]$ & --- & $x+\operatorname{cod}_{\mathbf{i}_{\mathrm{j}}^{\mathrm{v}: 2}}$ & ----- & $\forall g e \underset{\mathbf{b}_{\mathbf{j}} \mathbf{v}: 40}{n_{0}}$ \\
\hline$p=[$ ser $]$ & ---- & puicio & --- & \$piente \\
\hline$P=[$ con $]$ & --- & --- & ----- & $\underset{a_{a_{v i j i}{ }^{k i 21}}}{\operatorname{pox}}$ \\
\hline
\end{tabular}

Signos especiales heredados de la escritura manuscrita medieval

LÁMINA 10

\begin{tabular}{|c|c|c|c|}
\hline Toledo & Burgos & Zaragoza & Valencia \\
\hline ygl'a [iglesia] & gl'ia [gloria] ${ }_{\mathrm{C}_{\mathrm{v}} \mathrm{p}: 6}$ & gl'iosa [gloriosa] & ---- \\
\hline ------- & d'scl'pa [desculpa] & titl'o [titulo] $]_{\mathbf{f}_{\text {vijj }} \mathrm{R}: 25}$ & ----- \\
\hline ------ & cauall'os $\mathbf{f}_{\mathbf{f}_{\mathbf{j}} \mathbf{v}: \mathbf{l}}$ [caballeros] & angl'icico ${ }_{\mathbf{g}_{\mathrm{v} j} \mathrm{f}: 13}$ [angélico] & ----- \\
\hline
\end{tabular}

Apóstrofo detrás de la $\mathrm{L}\left(\mathrm{I}^{\prime}\right)$ 


\begin{tabular}{|c|c|c|c|}
\hline \multicolumn{4}{|c|}{ LÁMINA 11} \\
\hline Toledo & Burgos & Zaragoza & Valencia \\
\hline 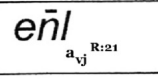 & $e \overline{k_{\mathrm{k}_{\mathrm{v}}}=23}$ & $\left.e \bar{n}\right|_{\mathrm{a}_{\mathrm{v}} \mathrm{v}_{2}: 2}$ & --------- \\
\hline ------ & 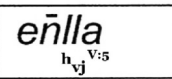 & ------- & - ----- \\
\hline 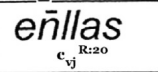 & ------ & ------ & ------ \\
\hline$e \bar{n} \underbrace{}_{\mathbf{e}_{\mathrm{ij}} v_{\mathrm{v}}}$ & 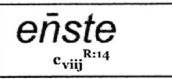 & 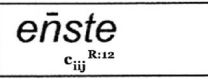 & ----- \\
\hline$e \bar{n} s t a$ & eñsta & $e \bar{n} s_{\mathbf{c}_{\mathbf{i j}}: 33} t a$ & ------ \\
\hline$e \bar{n} s t o$ & ----- & 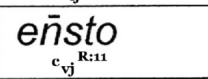 & ------ \\
\hline
\end{tabular}

Contracciones de la preposición en 
SÁnchez SÁnchez-Serrano, Antonio, "Las abreviaturas en cuatro ediciones tempranas de la Celestina: Toledo 1500, Burgos 1499-1502 (?), Zaragoza 1507 y Valencia 1514. Catalogación, cuantificación y consecuencias editoriales", Celestinesca 38 (2014), pp. 125-154. 